http://doi.org/10.35784/iapgos.568

\title{
ANALYSIS OF ALL-PASS FILTERS APPLICATION TO ELIMINATE NEGATIVE EFFECTS OF LOUDNESS WAR TREND
}

\author{
Wojciech Surtel, Marcin Maciejewski, Krzysztof Mateusz Nowak \\ Lublin University of Technology, Department of Electronics and Information Technologies, Lublin, Poland
}

Abstract. In this paper the influence of all-pass filters on musical material with applied hypercompression dynamics (loudness war trend) was analyzed. These filters are characterized by shifting phase in selected frequency band of signal, not by change of their amplitude levels. Because a lot of music information is present in music tracks, the dynamic range was tested together with influence of other sound parameters like selectivity or instruments arrangement on scene, by running subjective tests on a group of respondents.

Keywords: all-pass filters, digital filters, loudness war, dynamics compression

\section{ANALIZA ZASTOSOWANIA FILTRÓW WSZECHPRZEPUSTOWYCH DO ELIMINACJI NEGATYWNYCH SKUTKÓW TENDENCJI LOUDNESS WAR}

\begin{abstract}
Streszczenie. W artykule przeanalizowana wptyw filtrów wszechprzepustowych na materiał muzyczny z zastosowana hiperkompresja sygnału (tendencja loudness war). Filtry tego typu, charakteryzują się przesunięciem w fazie składowych częstotliwościowych, sygnału, a nie zmiana poziomu ich amplitudy. Ze względu na duża ilość informacji w utworach muzycznych, prócz sprawdzenia zakresu dynamiki poprzez testy obiektywne, zbadano również wpływ na inne parametry dźwięku takie jak selektywność czy rozłożenie instrumentów na scenie, poprzez testy subiektywne na grupie respondentów.
\end{abstract}

Słowa kluczowe: filtry wszechprzepustowe, filtry cyfrowe, loudness war, kompresja dynamiki

\section{Introduction}

The concept of progressing loudness war is closely related to the dynamic compression. In the 1960s it was noticed that louder songs played by a radio stations generate better sales results. Hence, many radio stations decided to use louder versions of songs. In this type of recording, the compression of the dynamics was limited due to the characteristics of analog sound medium (magnetic tape or vinyl disc).

The launch of a CD with a much greater dynamic range and discreet representation of signal has changed the approach to music production. Recordings production could take multiple compression and signal normalization. Hence, recordings with dynamic hyper-compression began to be created.

Recordings of this type have a similar intensity of sound throughout the duration of the song. Sounds coming from more quiet instruments are amplified, so that they have a similar level of signal as other sounds in a musical track. In such production, it is easier to hear all sounds appearing in environments with high noise [12]. This trend causes a number of negative effects. They include: tiredness of ears after sustained presence in the room, reduction of the stereo scene (sound seems to come from one direction) and creation of various artifacts in the sound (clipping, aliasing, overlapping of frequency bands).

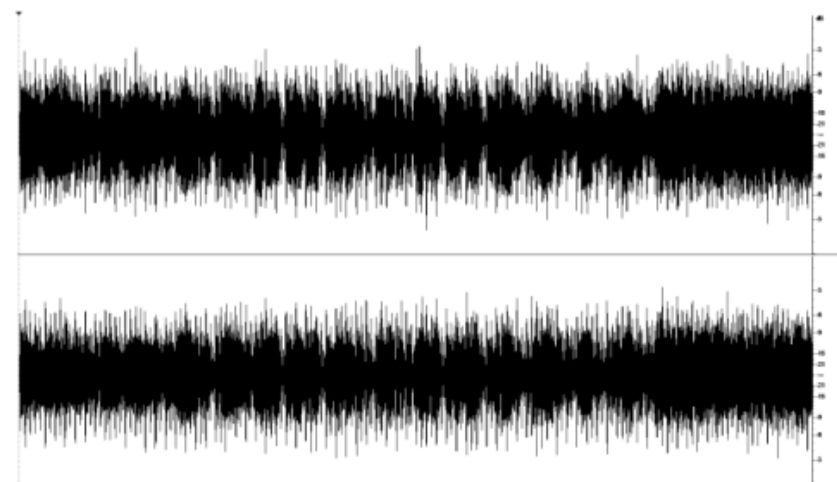

Fig. 1. Recording of the song Early Morning Wake Up Call in first vinyl editio from 1984. Despite the use of dynamic compression (similar amplitude level in the indicated fragment), the peak value of the signal is at the level of $-2.77 \mathrm{~dB}$, and the percussion instrument stands out from other instruments (visible sharp signal peaks)

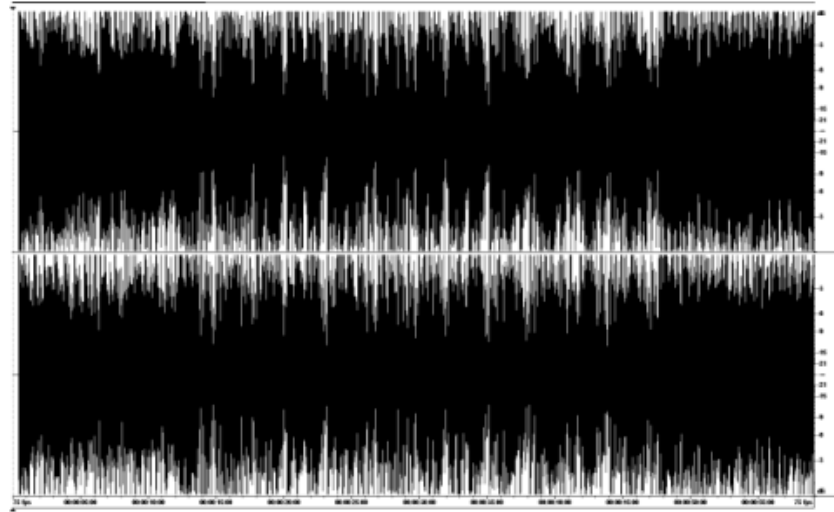

Fig. 2. Recording of the same song in remastered $C D$ version from 2012. The peak signal level reaches the maximum value for the 16-bit file range $(0 \mathrm{~dB})$. There are no sharp percussion peaks (they are cut with a limiter). The recording has applied hypercompression dynamic

In addition to using loudness war in the music industry, this trend is used in movies and commercials. There are standards for the production of this type of recordings, however, they primarily comply to the maximum level of signal amplitude. There is no valid document in Europe specifying the range of sound dynamics in the presented material, thus advertisers often use hypercompression of dynamics within the boundaries of limiter in accordance with to EBU R 128 loudness recommendation [5,9]. The material thus created still retains the negative effects of the above trend.

\section{The concept of removing effects of the Loudness War trend}

The use of dynamic hypercompressions is an irreversible operation. In order to attenuate its negative effects the influence of various signal processors was checked. Such processors and systems for use in audio signal processing can use a variety of operation algorithms. One of them are digital filters.

Digital filters in audio technology are used to remove or cut selected frequency bands of the signal. They are used particularly for muffled or noisy recordings. Unfortunately, they change the reception of the song by modification of pitch of the sound or masking high frequencies (occurring in lossy compression). Using the filter systems and the amplification module, a system called the equalizer is created [2]. It is often used to produce effects in popular music players. However, they do not have universal appli- 
cation, as the effect of its operation varies due to the type of music for which it is used.

The use of multiple signal compression cannot be reversed by using tools operating on the opposite principle. These tools (called dynamic processors) are signal amplifiers in a fixed ratio between different levels of the input signal. Using an expander (reducing the sound amplification for the given input range) can only partially reduce the negative impact of the trend. What is more, use of this tool is associated with sudden jumps in the level of noise, unnatural silence of the instruments and does not affect the clipping in any way [8].

\section{Description of all-pass filters}

There are various types of filters. Among these we can distinguished all-pass filters, used to shift the phase of selected frequency components or the entire frequency response. These filters differ from the others by maintaining a flat frequency response, so they do not cause differences in the pitch of the sound. They are most often used in loudspeakers and head-phones for correction of phase shifts introduced by low-pass filters. The formula for the impulse response of such a filter is [10]:

$$
\left(H\left(e^{j \omega}\right)\right)^{2}=1 \quad \forall \omega
$$

where: $\omega$ - frequency.

The use of very high-order filters can lead to shifting of different signal bands over time. This most often causes blurring transients of the percussion instruments. In the case of uncom-pressed recordings, the all-pass filter may slightly change the dynamics of the song. In addition, this type of filter is used in digital devices that create a reverb effect. Making a phase shift with a large angle on the lower frequency components will result in the extension of the bass sound and the increase of his participation [3].

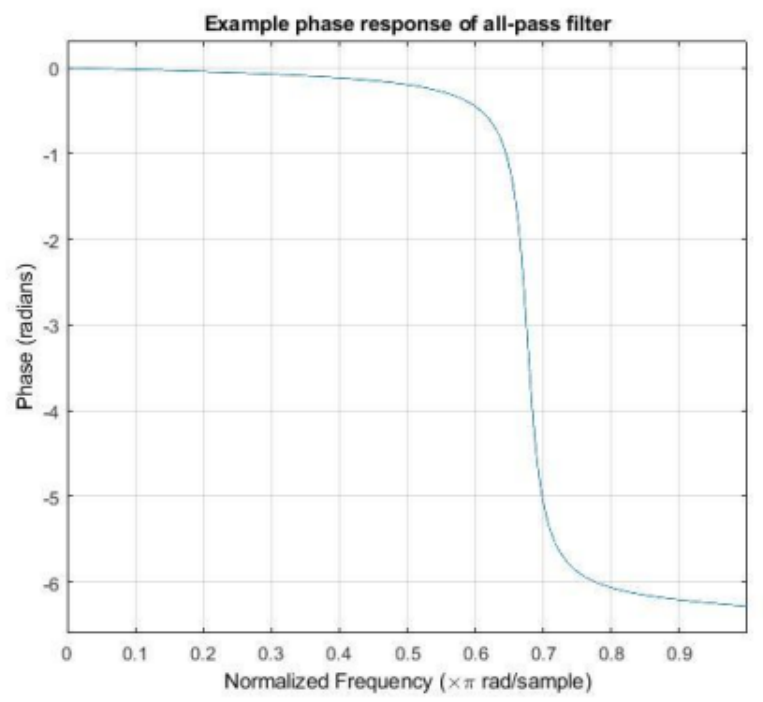

Fig. 3. Example phase characteristics of the filter with coefficients 1 and 0.9. The phase shift takes place in this case for higher frequency components by a full unit circle

\section{Description of the Adobe Audition application}

Adobe Audition (formerly Cool Edit Pro) is an audio editing environment created in the early 1990s. Purchased by Adobe in May 2003, it is being developed to this day. It contains many built-in digital filters and signal processors using which you can create your own characteristics. In addition, it includes fragment analysis tools and frequency or phase analysis for the audio signal. It supports many types of plugins, including the latest version of the VST3 plugin.

Version 1.5 (from May 2004) supplies is the Graphic Phase Shifter tools [1]. They are available from the Effects / Filters / Graphic Phase Shifter menu. It uses an all-pass filter with a userdefined phase characteristic. It is possible to set a the number of samples for which the fast Fourier transform will be calculated, choose the channel to shift, use the pre-made presets or save your own and use the approximation instead of the sharp transition of changes:

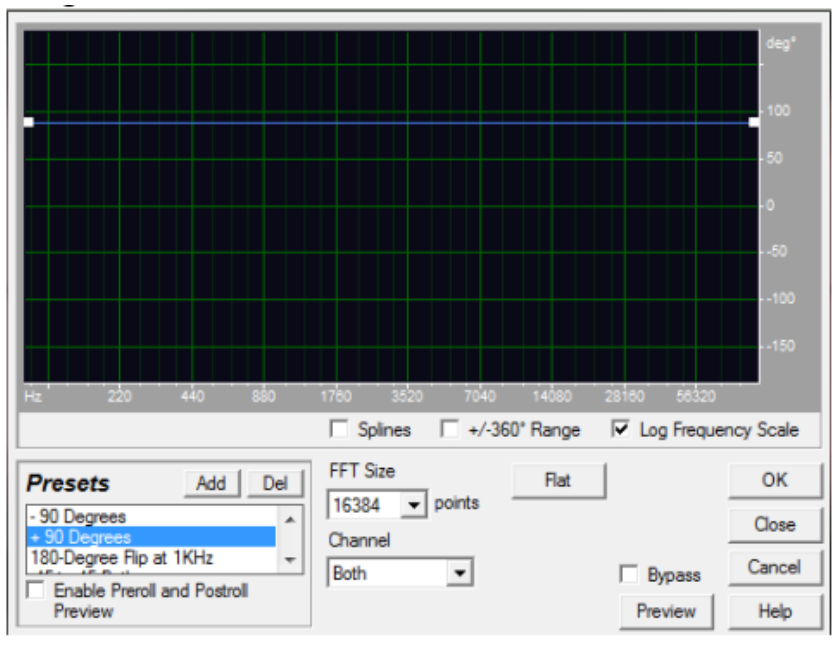

Fig. 4. View of the Graphic Phase Shifter window in Adobe Audition 1.5 with an example of a phase shift characteristic of $90^{\circ}$ for the entire frequency spectrum.

\section{Description of the experiment}

As a part of the experiment, objective tests of the dynamics and subjective tests to checking impact on other parameters assessed by the group of respondents were conducted. The objective tests were performed using the Dynamic Range Meter, created by the Pleasurize Music foundation and the loudness Meter tool included in the MATLAB Audio System Toolbox. The Dynamic Range Meter uses its own algorithm, dynamic unit (abbreviation DR) and assigns a scale to it. The formula is as follows:

$$
D R=\frac{1}{N} \sum_{n=0}^{N}\left(X_{\text {max }}-X_{e f}\right)
$$

where: $N$ - number of channels, $X_{\max }$ - signal peak in units of dBFS, $X_{e f}$ - effective value calculated for $20 \%$ of the most amplified part of the signal in units of dBFS.

The dBFS unit represents the gain level expressed in decibels below the full scale range for the file. The DR scale has been divided into 3 ranges: good dynamics values (values from 14 DR), transient dynamics (from 8 to $13 \mathrm{DR}$ ) and recordings with bad dynamics (values up to $7 \mathrm{DR}$ ). In addition, the foundation runs a generally accessible database of phonographic recordings and their dynamics due to the publisher [4].

The loudness Meter tool uses the LRA algorithm developed by TC Electronics for the EBU R 128 recommendation. The LRA algorithm measures the dynamics of the recording based on the statistical distribution of the measured loudness. The quietest $10 \%$ and the loudest $5 \%$ of the track are not included in the final result. The unit of dynamics is in this case LU (loudness unit) and there are no specific ranges for it because, unlike DR, its value depends on the length of the song. This algorithm is often used for television and radio recordings and for matching recordings to music streaming websites $[7,11]$.

All tests were conducted on six separate fragments of songs from various genres of music. A 30-second fragment was used for each selected song. The recordings in which hyper-compression of the dynamics in the source recording was observed were used. The result was additionally confirmed with the objective tests of the Dynamic Range Meter (values 7 and lower). The recordings were selected based on the genre variation and popularity of songs

For tests the following material was selected:

- Song 'All Nightmare Long' from Death Magnetic album by Metallica (thrash metal genre),

- Song 'Thriller' from Michael Jackson's compilation album Scream (pop genre, funk), 
- Title track from album Californication by Red Hot Chili Peppers (alternative rock genre),

- Title track from the Song of Delilah album by Cedar Walton Trio (jazz genre),

- Song 'House of Wax' from Paul McCartney album Memory Almost Full (pop rock),

- Song 'Moon Child' from the album Before the Dawn Heals Us from the M83 project (genre of electronic music).

Each of the presented songs has been transformed using the all-pass filter with two settings. The first of these (Figure 5) assumes a linear increase in the phase shift between the angle of $-45^{\circ}$ and the angle of $45^{\circ}$ for the linear frequency scale in the range from 0 to half of the material sampling frequency (44 $100 \mathrm{~Hz} / 2=22050 \mathrm{~Hz})$. The same shift was used for both channels in the stereo track. The second one (Figures 6 and 7), converts the signal by phase shift to $-90^{\circ}$ to $90^{\circ}$ for the left channel and decreasingly for the right channel for the same range.

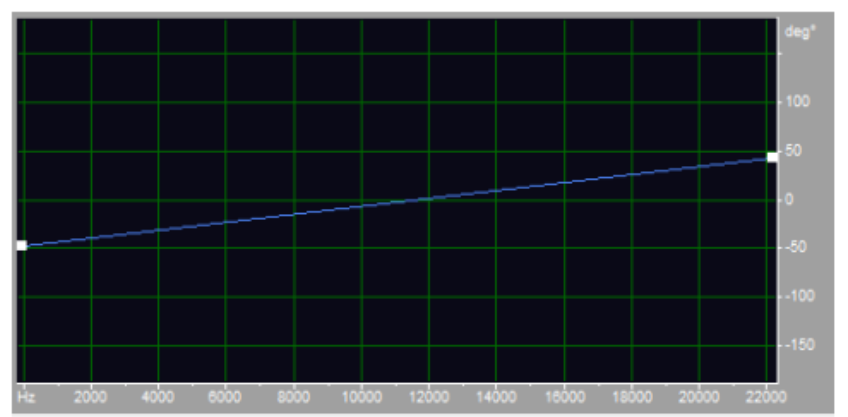

Fig. 5. Phase characteristic of the first of settings for both channels

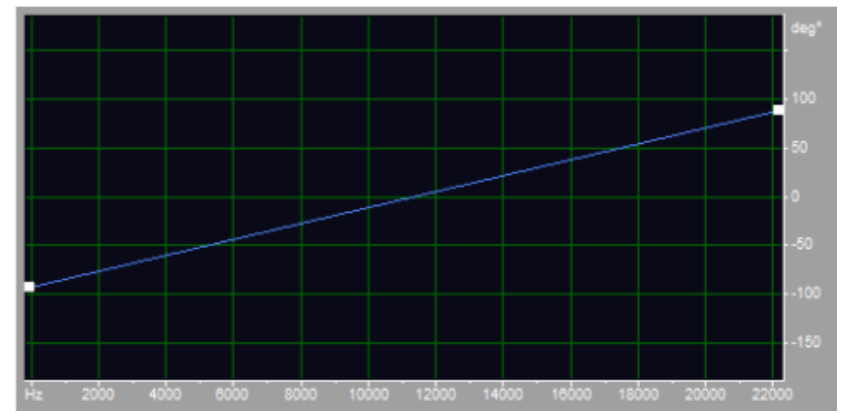

Fig. 6. Phase characteristic of the second set for the left channel

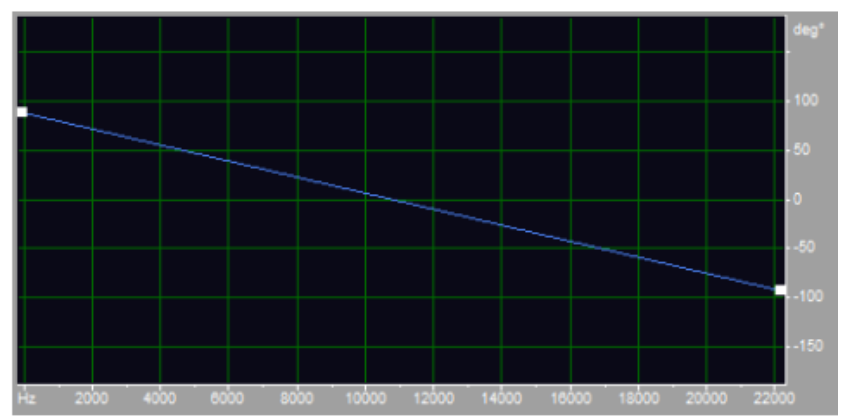

Fig. 7. Phase characteristic of the second of the settings for the right channel

Additionally, subjective tests were carried out on a group of 16 respondents, according to EBU Technical Review 274 [6], to check influence of all-pass filters on other parameters of the track. The test participants could assign grades according to recommendations as well as write their own feelings and comments on the musical material. The results of objective tests are presented in the tables below.

The results of the algorithm for measuring the dynamic range shows its growth using the phase shift. The smallest change can be observed for a jazz recording, the biggest for a metal song. Differences between the results exist due to the way drums participate in the recordings, the all-pass filter distinguished it the most by regulating the occurrence of its frequency components in time. The difference of 3 DR values, due to the use of the dBFS unit in the algorithm, is equivalent to the difference in the dynamic range of $3 \mathrm{~dB}$ for the entire fragment (twice increase in its range). Thus, in the case of the biggest difference between the original recording and the $90^{\circ}$ phase shift, we are dealing with a more than six-fold increase in the dynamics of the entire recording.

Table 1. The results of the fragment dynamics calculation using the Dynamic Range Meter

\begin{tabular}{|c|c|c|c|}
\hline Fragment/version nr. & Original & $45^{\circ}$ & $90^{\circ}$ \\
\hline All Nightmare Long & 4 & 12 & 14 \\
\hline Thriller & 7 & 13 & 14 \\
\hline Californication & 4 & 10 & 10 \\
\hline Song of Delilah & 7 & 9 & 9 \\
\hline House of Wax & 5 & 9 & 10 \\
\hline Moonchild & 6 & 10 & 10 \\
\hline
\end{tabular}

Table 2. Results of dynamics calculation using the LRA algorithm obtained with MATLAB software.

\begin{tabular}{|c|c|c|c|}
\hline Fragment/version nr. & Original & $45^{\circ}$ & $90^{\circ}$ \\
\hline All Nightmare Long & 1.36704729 & 1.36676814 & 1.36679966 \\
\hline Thriller & 1.19096398 & 1.19275449 & 1.18769888 \\
\hline Californication & 1.82118726 & 1.82028908 & 1.82093168 \\
\hline Song of Delilah & 1.27255432 & 1.27282393 & 1.27190181 \\
\hline House of Wax & 1.42241976 & 1.42180327 & 1.42164776 \\
\hline Moonchild & 1.40707177 & 1.40800176 & 1.40744225 \\
\hline
\end{tabular}

The results of the LRA algorithm show negligible changes between the original and processed fragments. This is because the influence of specific frequency components of the signal is shifted in time, and it is not cut or removed. In this case, the operation of the algorithm does not indicate that any of the filters causes an increase or decrease in the dynamics value. For versions processed with other signal processors (in particular the dynamics processor) the differences in the dynamics of the LRA algorithm are much greater. To explain the variation in the results of both algorithms for the all-pass filter, the corresponding waveforms are presented

Fig. 8. The original recording of the selected fragment All Nightmare Long. The average effective values of the signal for the fragment are: -18.6 dB for the left channel and $-19.96 \mathrm{~dB}$ for the right channel, respectively

The phase shift fragment has a significantly changed signal envelope, despite the same mean effective value of the signal for the whole fragment being compared to the same. Changes in the dynamics of the song are visible on the time courses, however, along with the increase of the dynamics of the song, you can observe unnatural peaks of the signal (in particular in places where in the original signal there were overloads). In exchange, there is no change in the amplitude of specific frequencies. Hence, the LRA algorithm did not show major changes (only differences in clipping samples). 


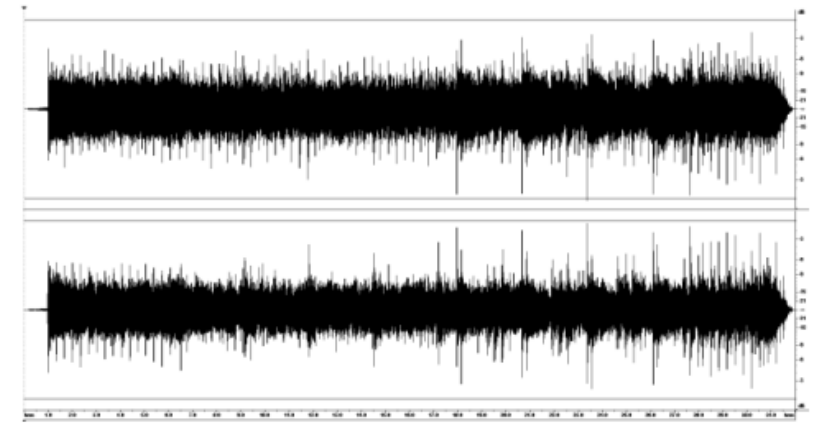

Fig. 9. The recording moved in phase according to the second setting of the selected fragment All Nightmare Long. The average effective values of the signal for the fragment are: $-18.62 \mathrm{~dB}$ for the left channel and $-19.98 \mathrm{~dB}$ for the right channel, respectively

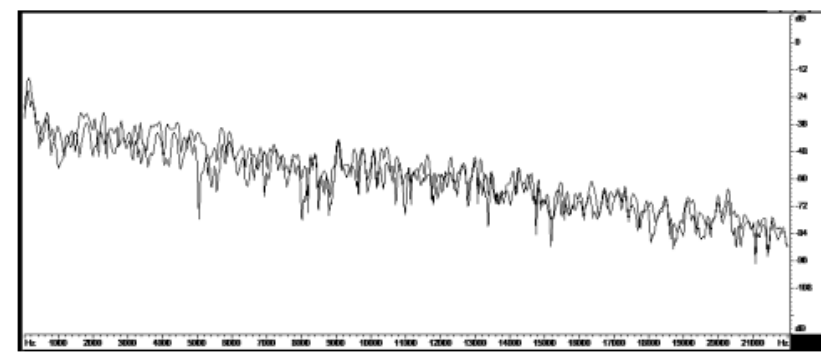

Fig. 10. Frequency analysis chart for 5 seconds of the original fragment under test identical to the processed one

Respondents participating in the subjective test compared fragments processed to original fragments. In this case, the larger fragment with a phase shift of $45^{\circ}$ (average 4.8) compared to the fragment with a $90^{\circ}$ shift (mean 4.4) obtained a better result.

According to participants, too large phase shift caused an incorrect distribution of instruments on the stage, also manifested by changing the direction of the sound (the impression that the sound reached the listener after bouncing off the wall). The influence of guitars, in particular the bass guitar, has increased. With a shift of $90^{\circ}$, this brought the instrument to the foreground. The version with a phase shift of $45^{\circ}$, did not have such clear differences from the original. Some of the people showed similar comments, but they were harder to hear from the second setting.

\section{Final conclusions}

All-pass filters introducing a shift in the phase of frequency components of the signal change the dynamics of the recording. For a loudness-war recording, there is a local signal amplification observed through the increase in signal peaks. The dynamics of recording is especially visible for percussion instruments. Clipping objectively increases. The second objective test, however, shows that these changes do not cause differences in the gain of specific frequencies. Hence, for a smaller phase shift, these changes are difficult to hear. The positive effect (audible in audition) of the processed versions is their effect on the clipped fragments. This can be seen in Figure 9.

As it has been noticed in fragments with a larger phase shift, there are additional problems with the lower frequency components of the signal. Therefore, it would be necessary to abandon linear and symmetrical characteristics completely in relation to the middle of the range. However, this results in a smaller difference in dynamics relative to the original.

\section{References}

[1] Adobe Audition CC, https://www.adobe.com/pl/products/audition.html (access: July 2018).

[2] Altunian G.: The Difference Between a Graphic and a Parametric Equalizer. https://www.lifewire.com/graphic-vs-parametric-equalizer-3134842 (access: July 2018).

[3] Berners D.: Q: What are allpass filters and what are they used for? https://www.uaudio.com/blog/allpass-filters/ (access: July 2018).

[4] Dynamic Range DB, http://dr.loudness-war.info/ (access: July 2018).

[5] EBU R 128, Loudness normalisation and permitted maximum level of audio signals. https://tech.ebu.ch/docs/r/r128.pdf (access: July 2018) Geneva 2014.

[6] EBU Technical Review 274, Subjective assessment of audio quality - the means and methods within the EBU. https://tech.ebu.ch/docs/techreview/trev_274hoeg.pdf (access: July 2018) Geneva 1997.

[7] EBU Tech 3342: Zakres głośności: Deskryptor uzupełniający normalizację głośności zgodnie z zaleceniem EBU R 128 .

https://tech.ebu.ch/docs/tech/tech3342_PL.pdf (access: July 2018) Geneva 2010.

[8] Jeffs R., Holden S., Bohn D.: Dynamics Processors -- Technology \& Applications https://www.rane.com/note155.html (access: July 2018).

[9] Orpheus R.: EBU R128 - The important audio breakthrough you've never heard of https://www.iconnectivity.com/blog/2017/6/10/ebu-r128-theimportant-audio-breakthrough-youve-never-heard-of (access: July 2018).

[10] Smith J.O.: Physical Audio Signal Processing, http://ccrma.stanford.edu/ jos/pasp/, online book, 2010 (access: July 2018).

[11] TC Electronics, Loudness Explained. https://www.tcelectronic.com/brand/tcelectronic/loudness-explained (access: July 2018)

[12] Vickers E.: The Loudness War: Background, Speculation and Recommendations. 129th AES Convention, San Francisco 2010.

\section{Ph.D. Eng. Wojciech Surte}

e-mail: w.surtel@pollub.pl

Graduated from the Faculty of Electrical Engineering in Lublin Institute of Technology. From 1989 to 2011 worked in the Department of Electronics in Lublin Institute of Technology. Obtained PhD degree in 1999 in the Faculty of Electrical Engineering in Lublin Institute of Technology. Since 2011 senior lecturer in Department of Electronics and Information Technology. Fields of study include teleinformatics, telemedicine, digital data analysis.

https://orcid.org/0000-0003-1166-4083

\section{Ph.D. Eng. Marcin Maciejewski}

e-mail: m.maciejewski@pollub.pl

He graduated from the Faculty of Electrical Engineering and Computer Science at the Lublin University of Technology. Since 2011 works in the Department of Electronics and Information Technology. Completed PhD thesis in 2019. Fields of study include medical data processing, telemedicine, robotics and microcontrollers.

https://orcid.org/0000-0001-9116-5481

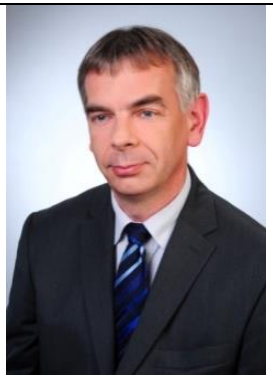

M.Sc. Krzysztof Mateusz Nowak

e-mail: krzysztof.mateusz.nowak94@gmail.com

He graduated from the Faculty of Electrical Engineering and Computer Science at the Lublin University of Technology in the field of Computer Science, specialization in Mobile Systems and Multimedia Techniques.

https://orcid.org/0000-0002-3117-7998

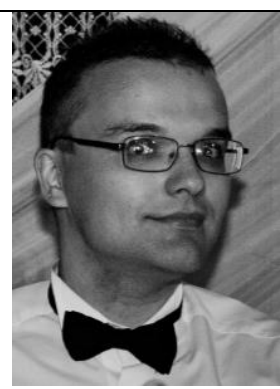

otrzymano/received: 28.10 .2019

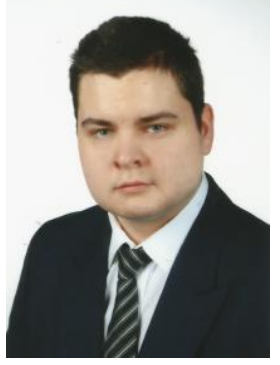

przyjęto do druku/accepted: 26.06 .2020 